\title{
Creating a Subject-based Learning Website: Cheese Technology Institute
}

\author{
Yuanyuan JIA ${ }^{1}$ Wei FU ${ }^{1}$ \\ College of Chemical Engineering and Material Science \\ Tianjin University of Science and Technology \\ Tianjin, China \\ E-mail: jiayuanyuan55@hotmail.com
}

\author{
Zheng $\mathrm{ZHAO}^{2}$ \\ College of Food Engineering and Biological \\ Technology \\ Tianjin University of Science and Technology \\ Tianjin, China \\ E-mail: zhaozheng3721@163.com
}

\begin{abstract}
Websites of 'Cheese Technology Institute' in English and Chinese version were launched by Cheese Lab of Tianjin University of Science and Technology (TUST) and Food specialty, Royal DSM N.V. Web-based autonomic learning is the future mode of acquiring knowledge, which is also the aim of our websites. Plentiful resources, professional online information, interesting cheese culture worldwide are supplied by our websites. The evaluation of the websites was done by a survey, and positive feedback was received. The Cheese Technology Institute on-line advanced the learning and research of the readers and also inspired their interest, which facilitated the autonomic learning.
\end{abstract}

Keywords-Website; Resources; Autonomic learning; Cheese technology

\section{INTRODUCTION}

Nowadays, with a rapid development of computer and information techniques, it's vital to figure out how to apply internet techniques on teaching, improve the traditional teaching methods, supply plentiful learning resources as well as construct a tridimensional studying platform with lower learning and teaching difficulty but higher efficiency, which has become the significant content of educational reform in all colleges and universities. Among them, constructing and utilizing subject-based websites has drawn a lot of attention. Subject-based websites, with URL, usually have one or several learning themes concerning about one or several courses, which can be open to the public. And subject-based websites in colleges are made for deep learning to students on some projects during professional courses teaching. They are the assistance and extension of professional courses teaching, and serve as interdisciplinary network learning platforms, being different with traditional education. Nowadays, network technology is advancing by leaps and bounds. It is evident that E-learning is gradually becoming the mainstream of future learning [1, 2].

Subject-based websites developed by universities have subjects related closely to one or several courses concerning certain subjects, offering approaches to profound learning for students.

Cheese Lab of Tianjin University of Science and Technology (TUST) and Food specialty of Royal DSM N.V. jointly developed the websites of Cheese Technology Institute in both Chinese and English version. The aim is to supply plentiful information and resources to students, so as to guide them into autonomic learning. Moreover, it provides professional materials for cheese manufactures including forms of texts, videos and audios. Public may acquire up-todate research progress, cheese production techniques and history \& culture on cheese worldwide. It has been reported by some News Media, such as 'Science and

Technology Daily' on Apr. 13, 2010 http://www.stdaily.com/kjrb/content/2010-04/13/content 174582.htm, 'China Food Industry’ [3], 'China Dairy' [4], 'China Dairy Industry' [5], and 'Science and Technology of Food Industry’ [6].

Since the Chinese website was launched in 2010, it was visited more than 77,000 times and the English version was visited more than 32,000 times. It can be found on 'BaiDu' Search Engine by inputting 'Cheese technology institute' in Chinese.

This paper concentrates on the construction of our websites on Cheese Technology Institute.

\section{CONSIDERATIONS OF BUILDING WEBSITES ON CHEESE TECHNOLOGY INSTITUTE}

The aim of building the subject-based learning websites on Cheese Technology Institute is to provide an autonomic learning platform for students, supply teaching resources for teachers, and offer an international vision for our students. The page design is vital in style, simple in color, and concise in structure. The dominant hue is yellow, and the LOGO is a traditional Chinese seal. Color harmony is considered in designing the web pages http://www.cheeseinstitute.com/ and http://www.cheesetechinstitute.com/, as shown in Fig. 1. There is a 'Cheese BBS', where teachers and students may exchange ideas freely.

\section{LAYOUT DESIGN}

The rule of designing a website lies on its practicality and efficiency $[7,8]$. The navigation of our website is clear. There is a horizontal navigation bar on the home page. The lower catalogue will spread when the mouse slips over the navigation bar. The secondary page has a vertical catalogue, showing the content of a secondary column under a primary catalogue. The number of hyperlinks is no more than three to ensure smooth linking. There are bottoms of 


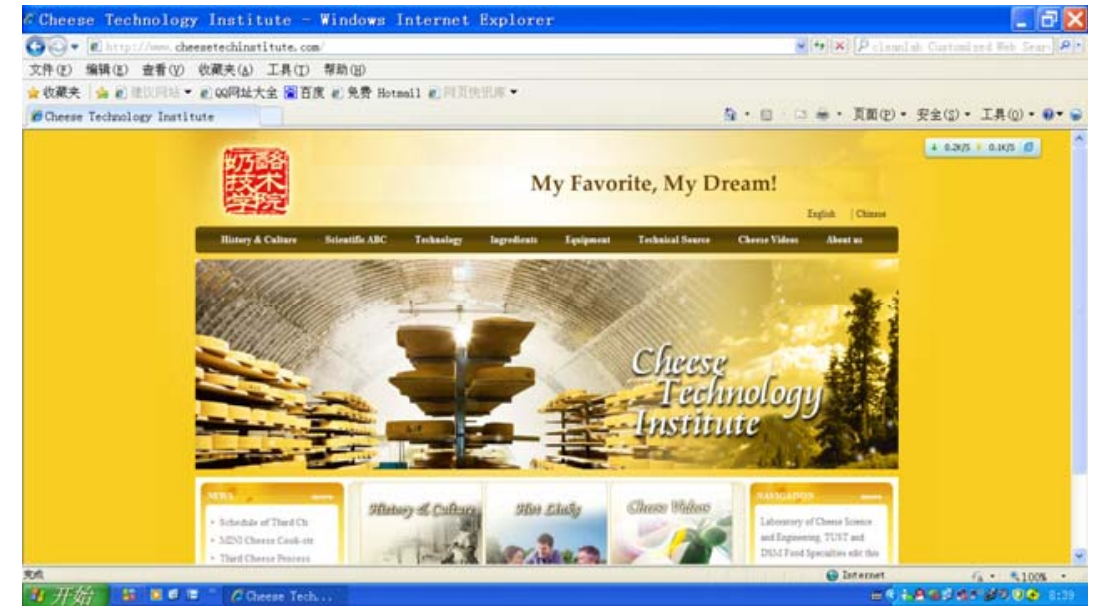

Figure 1. The homepage of the Cheese Technology Institute.

'Backstage' on the bottom of both sites to make updates easy. Most contents, including PPTs, books, videos are hyperlinks to relevant sites, which is different from our other sites [9]. By doing like this, readers are given additional information from relevant sites. A counter is used to record the number of visits.

\section{MAIN CONTENTS}

There are eight first-level catalogues covering the majority of cheese technology, with the framework of our websites shown in Table 1 .

It is of importance that our websites provide web-based autonomic learning resources and platform for students. It supports a learning model of combining class, extracurricular activities and internet.

Our websites offer 44 online videos, including various types of cheese, cheese processing techniques, cheese plants, cheese equipment, etc.

TABLE I. FRAMEWORK OF THE WEBSITES

\begin{tabular}{|l|l|}
\hline First level & Second level \\
History \& Culture & History, Culture, Cooking \& Serving \\
Scientific ABC & Microbiology, Chemistry, Engineering \\
Technology & Hard cheese, Semi-Hard cheese, Mould \\
& cheese, Soft cheese, Processed cheese \\
Ingredients & DSM, Suppliers \\
Equipment & Industry, Laboratory \\
Technical Source & Books, PPTs, Websites \\
Cheese Videos & Web videos, TUST videos \\
About us & English version \\
Cheese BBS & Chinese version \\
\hline
\end{tabular}

The sources of these videos are as followings, 'How it's made' in 'Discovery' channel', 'Agricultural World' of CCTV-7, worldwide science \& education webs, such as the video resources on the website of INSTITUTE OF FOOD TECHNOLOGISTS (IFT), 'The Great Food Fight' and 'From Concept to Consumer: Food Product Development'
(http://members.ift.org/IFT/Education/EduResources/mediar esource.htm) ; 'How everyday things are made' from Stanford University (http://manufacturing.stanford.edu/); 'Food Safety Videos' from US Food and Drug Administration (http://manufacturing.stanford.edu/); 'Space Food Videos' from NASA Food Technology Commercial Space Centre (http://www.ag.iastate.edu/centers/ftcsc/pages/educate.htm\# vids). We have a video resource library on website of 'Youku'. All of the videos on websites of Cheese Technology Institute are hylinks to the video library on 'Youku' (http://www.youku.com/), which is different from the two course websites we have made before ${ }^{[2]}$. The benefit is to avoid occupying huge bytes on the Web Server.

There are also videos filmed in our university, including lectures and experiments. Readers can find free downloadable E-books, PPTs and websites from the column of 'Technology Source'. Processing technologies of various cheeses, including Romano cheese, Swiss cheese, etc are illustrated on the column of 'Technology'.

\section{TECHNICAL SOLUTIONS}

The operating system of the webs of 'Cheese Technology Institute' is Windows XP. Static web pages are written by ASP (Active Server Pages). Some pictures and animation materials are treated and transformed by PHOTOSHOP CS 4. The animations are made by MACROMEDIA FLASH 8.0. Video files are edited by Adobe Premiere Pro CS4, and uploaded to the website 'Youku' (www.youku.com). Word files are transformed into FLASH by Macromedia Flash Paper 2.0.

\section{SURVEY AND EVALUATION}

Visitors were asked to complete a survey by clicking a link 'Questionnaire' on the bottom of the homepage. The result can be viewed on the backstage. 56 responses were 


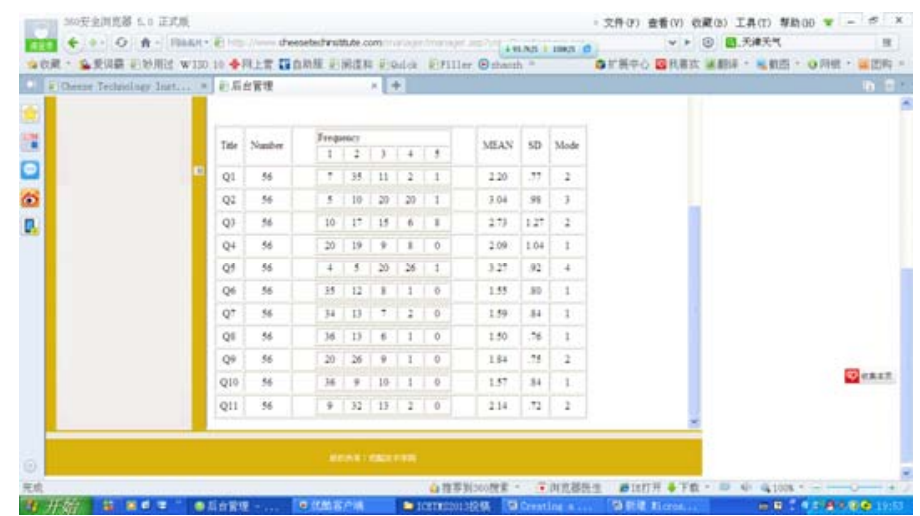

Figure 2. The statistics of the survey on the Backstage

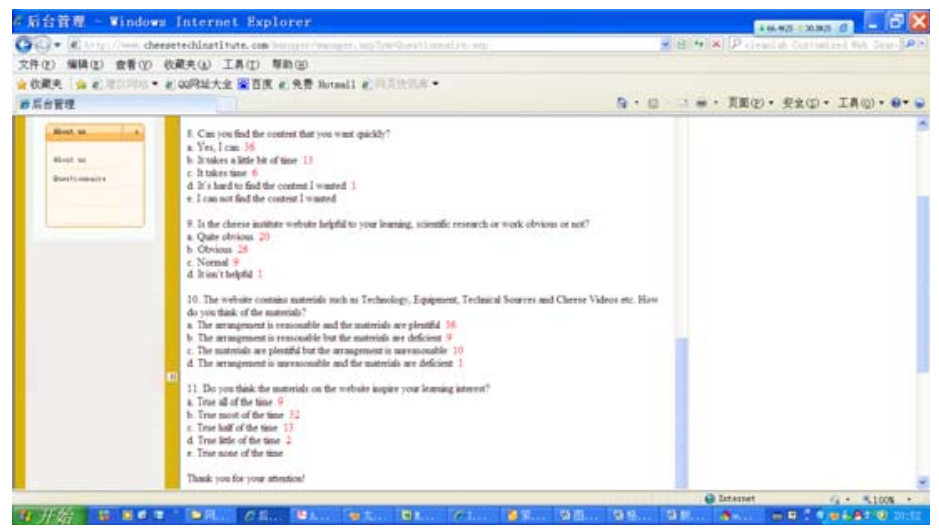

Figure 3. Question 8, 9, 10, and 11 and their responses of the survey on the Backstage

received and analyzed. Fig. 2 shows the mean, standard deviation, and mode of the results, for each question of the survey. Fig.3 shows question 8, 9, 10, and 11 and their responses.

From the results, it was found that $12.5 \%$ of the participants of the investigation had doctoral degree, and $62.5 \%$ had master degree, while another $19.6 \%$ had bachelor degree. It was also found that, $8.9 \%$ of the respondents were company R \& D staffs, $17.9 \%$ were university teachers, $35.7 \%$ were postgraduates, and another $35.7 \%$ were university students. Around $35.7 \%$ of the respondents visited the Cheese Technology Institute frequently, and $33.9 \%$ of the respondents often visited the website. Over $35.7 \%$ of the participants visited the website to know certain special subjects, and $46.4 \%$ of them visited it to search for some information related. Over $60 \%$ thought that the design is attractive and the layout is convenient to browse. Furthermore, over $60 \%$ of the respondents believed that the navigation and classification is quite distinct, and they can quickly find the content. When the respondents were asked to comment on the efficacy of the website, $35.7 \%$ of the respondents said that the cheese website was quite helpful to their learning, scientific research or work; another $46.4 \%$ said that the help from the website was obvious. Among the participants, $64.2 \%$ thought that the arrangement was reasonable and the materials were plentiful. Over $75 \%$ of the respondents said that the learning interest was inspired by browsing our website.

The feedback we received was quite positive. Readers believed that the layout and navigation were attractive, and our website provided useful information and materials to advance their learning and work. Importantly, the learning interest was developed to facilitate autonomic learning.

\section{MAINTENANCE AND RENEWAL}

It is necessary to renew the webs to make them vigorous and attractive to students and readers. There is News bulletin on our webs. We often release novel trends on the News bulletin. For example, we launched the success of mini-cheese cook stretcher in Sep. 2011. We held the second and the third Cheese Technology Seminar in 2010 and 2011. The Information and schedules were launched on the News Bulletin. Lectures of the seminars are displayed on the webs (under the catalogue of 'Cheese Videos'). We will film more experimental videos, and organize students to write texts and bilingual subtitles for videos.

\section{CONCLUSION REMARKS}

It is useful to built students' capability of creative thought and innovation ability via promoting thematic learning and studying, since subject-based websites give 
essential environment and an implement platform to it. Students will catch a further understanding of knowledge by using the website's functional modules and learning autonomously, curiously and cooperatively. Thus, we can develop students' learning interest via information technology and make them capable of transferring something strange into understandable and catchable by means of modern teaching tools. Therefore, learners acquire knowledge not simply in the way of acceptance or copy but the way of active construction. The websites of 'Cheese Technology Institute' afford abundant learning resources to facilitate web-based autonomic learning for students. Students enlarge their views and enrich their professional knowledge by means of exploring and studying the subjected-based website. It is also an exchanging platform for students, teachers and public. Up to now, our Chinese Cheese Technology Institute has been visited over 70 thousand times.

On the other hand, lifelong learning is upon us. Subjectbased websites provide flexibility and guidance for learners.

\section{ACKNOWLEDGMENT}

This paper is supported by the National Bilingual Demonstration Course Introduction to Food Science and Technology

\section{REFERENCES}

[1] L.N. Liu. "Designing an autonomic interactive learning environment based on Moodle,” Shandong Textile Economy, No. 11, pp. 98-99, 2011.

[2] X.W. Dou. "Training of web-learner's ability under the visual threshold of learning society," Continuing education, No. 12, pp. 3637, 2011.

[3] "Cheese Technology Institute run jointly by Food specialty, Royal DSM N.V.,” China Food Industry, No. 4, pp. 8, 2010.

[4] "Cheese Technology Institute run jointly by Food specialty, Royal DSM N.V.,” China Dairy, No. 4, pp.118, 2010.

[5] "Cheese Technology Institute run jointly by Food specialty, Royal DSM N.V.,” China Dairy Industry, No. 3, pp. 36, 2010.

[6] “Cheese Technology Institute run jointly by Food specialty, Royal DSM N.V.,” Science and Technology of Food Industry, No. 5, pp. 60, 2010.

[7] T. Li, Z. Gao, Q. Chen. "Construction of bilingual course 'Introduction to Nursing Science,” Morden Nursing, volume. 15, No. 6, pp. 576-577, 2009.

[8] J. H. Tan. "Construction and study on national excellent course web of our college," China Education Information: Vocational Education \& Higher Education, No. 23, pp. 25-26, 2008.

[9] Yuanyuan Jia, Zheng Zhao. "Design and Establishment of Website of Bilingual Demonstration Course,” 2010 International Conference on E-Business and E-Government, pp. 5409-5411, 2010. 